\title{
Analysis of Immunization Program Management in Achieving Universal Child Immunization (UCI) Coverage at Bebesen Health Center, Central Aceh Regency
}

\author{
Thomson P. Nadapdap ${ }^{1}$, Asyiah Simanjorang ${ }^{1}$, Suparti ${ }^{2}$ \\ ${ }^{1}$ Lecturer of Master Faculty of Public Health Institute, Helvetia Health, Medan, Indonesia \\ ${ }^{2}$ Student of Master of Public Health Program, Helvetia Institute of Health, Medan, Indonesia \\ Received: November 13, 2021 \\ Received in Revised: December 12, \\ Accepted: December 25, 2021 \\ 2021
}

\begin{abstract}
The purpose of the study was to analyze the implementation of immunization program management in an effort to achieve UCI at the Bebesen Health Center, Central Aceh Regency. This research uses descriptive qualitative method. The research location is Bebesen Public Health Center, Central Aceh Regency. Sources of data used consisted of primary data, secondary data and tertiary data. Data collection techniques in the form of observation, in-depth interviews with 10 informants and documentation. Data analysis techniques are carried out through data reduction, data presentation and drawing conclusions. To analyze the availability of resources for the implementation of the immunization program at the Bebesen Health Center, Central Aceh Regency, the researchers used management theory including input, process and output consisting of the availability of officers, sources of funds and facilities and infrastructure. The implementation of the immunization program consists of planning, implementation, monitoring and evaluation. The output can be seen in the UCI coverage at the Bebesen Health Center. It has not yet reached the target where the achievement is still $71.4 \%$. The conclusion of this study is that the staff's resources have met the qualification standards, namely having a medical or nursing educational background and having STR with a minimum education of DIII in the field of Health, as well as sufficient funds, facilities and infrastructure. The evaluation has been carried out and it is necessary to increase cross-sectoral collaboration.
\end{abstract}

Keywords: Immunization Program Management Analysis, Bebesen Health Center, UCI

\section{Introduction}

The application of management functions is a problem that often occurs in puskesmas, where the puskesmas is the front line in a community health service group. Health management functions such as scheduling, regulation, implementation, and monitoring must be able to be carried out for every health service, especially the immunization program which is required for a person as part of the community in order to protect the person concerned and the surrounding community from diseases that can be prevented by immunization (Situmorang, 2020).

The United Nations Children's Fund (UNICEF) 2017 report as many as 110,000 people, mostly small children, died from measles, the high death rate from measles can actually be prevented by implementing immunization. WHO-UNICEF places Indonesia fourth in the world after India, China and Nigeria in terms of the largest children who do not receive immunization services. WHO says an estimated 19.9 million babies worldwide are not covered by basic immunization services such as three doses of the Diphtheria-Tetanus-Pertussis (DTP) vaccine in 2017. Approximately 60 percent of these children live in 10 countries, Afghanistan, Angola, Democratic Republic of Congo, Ethiopia, India, Indonesia, Iraq, Nigeria, Pakistan and South Africa. The average immunization anticipates two to three million deaths per year. WHO

Copyright $@ 2021$, Journal of Asian Multicultural Research for Medical and Health Science Study, Under the license CC BY-SA 4.0 
annually commemorates World Immunization Week (PID) which has the goal of preventing millions of deaths from vaccine-preventable diseases. The campaign theme at PID 2018 was Protected Together to encourage greater action on immunization around the world. Immunization saves millions of lives and is recognized as the most successful and effective health intervention in the world (Situmorang, 2020)

Based on data from the Central Aceh Health Service, Bebesen Health Center, the achievement of complete basic immunization services in these 4 years has experienced ups and downs, namely in 2017 (73.0), 2018 (74.0), in 2019 there was an increase from the previous 2 years to $(80.2 \%)$ and in 2020 there was a decline again to $(71.8 \%)$ this was due to the low awareness and knowledge of the community about the benefits of immunization, the timing of immunization services, and post-immunization follow-up symptoms. Meanwhile, the achievement of UCI villages in Central Aceh Regency can approach the target set in the 2019 Mid-Term Development Plan, namely the achievement of UCI in 2016 (98\%), in 2017 (98\%), in 2019 (99\%) and in 2020 there is a decline. be (81.1\%). Meanwhile, the achievement of UCI at the Bebesen Health Center also experienced ups and downs, in 2017 it reached $97.0 \%$, in 2018 it decreased to $62.2 \%$ this was due to the introduction of a new vaccine, namely measles rubella, then in 2019 there was an increase again to 82, 1\%, and in 2020 there was another decline in UCI villages to $71.4 \%$ (Profilkes Ateng, 2020)

The main cause of the low achievement of UCI (Universal Child Immunization) at the Bebesen Health Center is because the provision of complete basic immunization services is more than the specified time, which is 9 months requiring immunization services, but given more than 9 months so that its function has reduced and can be said to drop out. This happens because the service schedule is not in accordance with community activities, low public awareness and knowledge about the benefits of immunization, timing of immunization, and postimmunization follow-up symptoms (Engler et al., 2015). Cultural and educational factors as well as socio-economic conditions also influence the low achievement of village UCI (EnginDemir, 2009).

\section{Methods}

In conducting the research used qualitative methods with descriptive design. Qualitative research according to Sugiyono (2007:68) is a research method that views the reality in the field as something that is comprehensively systematic and full of meaning and inductive mindset. In this study, the researcher acts as a data collector and as an active instrument in an effort to collect data in the field, so the researcher as an instrument validates the preparation for conducting research before entering the research field.

\section{Results and Discussion}

\section{Planning}

\section{Determining the number of targets}

The following are the results of an interview with the head of the disease prevention and control division of the Central Aceh District Health Office regarding targeting at the Bebesen Health Center:

"In planning for the district at the end of each year, we distribute the data collection format for immunization targets and puskesmas to collect data on vaccination targets and then distribute it to the village midwife for data collection on targets in each village - each immunization target is babies, so we need baby data in each new village and sub-district. we can determine how many targets." 
According to the Manager of the Regency Immunization Program, Mr. UA in an interview on 4 September 2021 regarding setting targets in the implementation of the immunization program stated that;

"Calculating the number of babies for children aged 0-11 months who have not been fully immunized, plus pregnant women who are fartus in the current year"

Meanwhile, according to the Head of Bebesen Health Center, Mr. dr. IV in an interview on 5 September setting targets in the implementation of the 2021 immunization program said that:

"The determination of the target number is usually obtained from the Central Aceh District Health Office, namely estimated data from statistics, because the data in the field is very different from the data we receive, usually the data they receive is larger than the data in the field, so sometimes that's the cause of the low immunization here."

According to the Bebesen Health Center immunization program manager, Mrs. M stated that in determining the targets in the implementation of the immunization program, interview on 6 September 2021:

"By counting the number of infants aged 0-11 months who have not yet been fully immunized, plus pregnant women who will give birth in that year, the immunization target is babies, so we need data on babies in each village and sub-district, then we can determine how many. number of targets"

The results of an interview with the village midwife of Kampung Sadong Juru Mudi, Mrs. E, on September 7, to determine the targets for implementing the 2021 immunization program, she said that:

"Calculating the number of babies in my work area in one year and added again to the count of pregnant women who are fartus in the current year".

Meanwhile, the village midwife of Kampung Atu Gajah, Ibu R, in an interview on September 8,2021 , in setting targets for the implementation of the immunization program, said that:

"Calculating the number of babies who have not been fully vaccinated and the number of pregnant women in the year they gave birth"

Likewise, the statement from the village midwife of Kampung Mongal Ibu A on September 4, 2021 setting targets in the implementation of the immunization program said:

"Calculating the number of babies in the village of empus talu in one year and adding more to the count of pregnant women who are fartus in the current year"

Meanwhile, according to the information from the village midwife of Kampung Blang Gele, Ms. $M$ in an interview on September 9, 2021, setting targets in the implementation of the immunization program stated that:

"Calculating the number of babies in the working area of the Blang Gele village in one year and adding it again to the calculation of pregnant women who gave birth in the current year"

Meanwhile, the village midwife of Kampung Empus Talu, SM, in an interview on September 3, 2021, set targets in the implementation of the immunization program stating that:

"Calculating the number of babies in the village of empus talu in one year and adding more to the count of pregnant women who are fartus in the current year".

The village midwife of Kampung Blang Kolak 2, SBA, in an interview on September 3, 2021,

Copyright (O) 2021, Journal of Asian Multicultural Research for Medical and Health Science Study, Under the license CC BY-SA 4.0 
set targets for the implementation of the immunization program, stating:

"Calculating the number of babies in the working area of Kampung Blang Kolak 2 in one year and adding more to the calculation of pregnant women who gave birth in the current year"

Based on the results of all these interviews, it shows that planning in determining the number of targets for the immunization program has been obtained at the beginning of each year from the Health Office based on population mobility, which is calculated based on the population, number of children under five, and number of babies last year obtained from BPS and Pusdatin data using the formula. Determination of the number of targets at the District Health Office for Puskesmas is obtained from the Pusdatin to see the population which will then be processed by statistics and from BPS data to see how many women and men are and their age which will then be calculated into per Kelurahan and per Puskesmas.

\section{Determining Coverage Targets}

The following are the results of an interview with the head of the disease prevention and control division of the Central Aceh District Health Office regarding the determination of the Coverage Target at the Bebesen Health Center:

"Target targets are set at the end of the year in order to achieve the national target of 95\% for each type of vaccination, then district targets from all puskesmas are collected and divided into 12 months so our monthly targets will appear."

According to the Immunization Program Manager of the Central Aceh District Health Office, Mr. UA in an interview on September 4, 2021, the determination of the Coverage Target stated that;

"The target target in 2020 is 95\% in each type of vaccination, usually divided into 12 months in 1 year to become the monthly target target."

Meanwhile, according to the Head of Bebesen Health Center, Mr. dr. IV in an interview on 5 September 2021 in determining the Coverage Target said that:

"The target given by the district to the Bebesen Public Health Center in 2020 is 100\% for each type of vaccination, usually the program manager will divide the 12 months in 1 year into the monthly target target of our puskesmas".

According to the Bebesen Health Center immunization program manager, Mrs. M stated in an interview on 6 September 2021 that the determination of the Coverage Target stated:

"The existing target is $100 \%$ divided by 12 months into the target year for the Puskesmas Bebesen, our monthly target is 8.3\% with the 2020 target of 696 babies. With the number of villages as many as 28 villages and which reached UCI only 19 villages, the others did not achieve UCI".

The results of an interview with the village midwife of Kampung Sadong Juru Mudi, Mrs. E, on September 7, 2021, to determine the Coverage Target, she said that:

"The target at the beginning of the year given by the puskesmas is 100\% divided by 12 months, so, my monthly target is to get $8.3 \%$ per month with 9 babies, the target number that must be vaccinated but does not reach the target".

Meanwhile, the village midwife of Kampung Atu Gajah, Ibu R, in an interview on September 8, 2021, to determine the Coverage Target, said that: 
"The target at the beginning of the year given by the puskesmas is $100 \%$ and then I will share it with 12 months so, my monthly target is to get $8.3 \%$ in a month with the number of babies in my work area, there are 10 babies in a year that I have to vaccinate"

Likewise, the statement from the village midwife of Kampung Mongal, Ibu A on September 4, 2021, said:

"The target at the beginning of the year given by the puskesmas is 100\% divided by 12 months so, my monthly target is to get $8.3 \%$ per month with the number of babies in my work area as many as 40 babies who must achieve complete basic immunization in the current year and the monthly target I have to achieve 3 complete basic immunizations every month"

Meanwhile, according to the information from the village midwife of Kampung Blang Gele, Ms. M in an interview on September 9, 2021, the determination of the Coverage Target stated that:

"The target at the beginning of the year given by the puskesmas is 100\% divided by 12 months, so my monthly target is to get $8.3 \%$ per month with the number of babies"

Meanwhile, the village midwife of Kampung Empus Talu, Mrs. SM, in an interview on September 3, 2021, to determine the Coverage Target stated that:

"The target at the beginning of the year given by the puskesmas is 100\% divided by 12 months, so my monthly target is to get $8.3 \%$ per month with the number of babies in my work area as much as"

The village midwife of Kampung Blang Kolak 2, SBA, in an interview on September 3, 2021, to determine the Coverage Target stated:

"The target at the beginning of the year given by the puskesmas is 100\% divided by 12 months, so my monthly target is to get $8.3 \%$ per month with the number of babies"

Based on the results of all these interviews regarding how to determine the coverage target, it shows that the determination of the coverage target is determined by the District Health Office which is adjusted to the number of residents and children under five in the Puskesmas working area.

\section{Determining the Need for Vaccines}

The following are the results of an interview with the head of disease prevention and control at the Central Aceh District Health Office, Mr. Iw, regarding the need for vaccines:

"In calculating the need for vaccines, there must be a target number of babies to be vaccinated for 1 (one year) for all types of vaccines".

According to the Immunization Program Manager of the Central Aceh District Health Office, Mr. UA in an interview on 4 September 2021 regarding the need for vaccines stated that;

"If you plan a vaccine, you must first know the number of immunization targets, coverage targets, calculate the vaccine use index, then you can determine how many vaccines are needed, then it will be given to the health office and then the health office will make a proposal to the province"

Meanwhile, according to the Head of Bebesen Health Center, Mr. dr. IV in an interview on 5 September 2021 regarding the need for vaccines said that:

"Calculating the target number of infants, toddlers and pregnant women as well as 
school-age children to be able to find out the need for vaccines in one year".

According to the Bebesen Health Center immunization program manager, Mrs. M stated in an interview on September 6, 2021 regarding the need for vaccines, she stated:

"The calculation is calculated every month according to the number of targets who want to be immunized, then we send the results of the report to the health office"

The results of an interview with the village midwife of Kampung Sadong Juru Mudi, Mrs. E, on 7 September 2021. Her vaccine needs said that:

"Every month, plan the number of vaccines according to the number of babies and the number of posyandu in the village".

While the village midwife of Kampung Atu Gajah, Ibu R, in an interview on September 8, 2021, Vaccination needs said that:

"It is adjusted to the target number that we will inject every month, that is our reference in taking the vaccine to the puskesmas."

Likewise with the statement from the village midwife of Kampung Mongal, Ibu A on September 4, 2021, Vaccine needs said:

"Adjusted with the number of targets/monthly targets that we will inject every month".

Meanwhile, according to the information from the village midwife of Kampung Blang Gele, Ms. $M$ in an interview on September 9, 2021, she stated that:

"It is adjusted to the target number that we will inject every month."

Meanwhile, the village midwife of Kampung Empus Talu, SM, in an interview on September 3, 2021 stated that:

"Adjusted with the number of targets/monthly targets that we will inject every month."

The village midwife of Kampung Blang Kolak 2, SBA, in an interview on September 3, 2021, stated:

"It is adjusted to the target number that we will inject every month."

Based on the results of all interviews regarding the determination of vaccine needs, it shows that planning for vaccine needs is absolutely obtained from the Health Office based on the need for vaccines every month adjusted to the number of targets and the amount of coverage of each vaccine using the index formula for the Vaccine Use Index (IP).

\section{Determining the needs of syringes, safety boxes and cold chains}

The following are the results of an interview with the Head of Disease Prevention and Control at the Central Aceh District Health Office Sir Iw regarding the need for injection equipment, safety box b and cold chains:

"The calculation is the same as the need for vaccines, we have to calculate the target, be it babies, under-fives, pregnant women, and school age children in one year and then add $15 \%$ vastagerate to prevent the possibility of damaged logiatics."

According to the Immunization Program Manager of the Central Aceh District Health Office, Mr. UA in an interview on September 4, 2021, the need for syringes, safety box b and cold chains stated that; 
"Referring to the target number of infants, under-fives, pregnant women, school age last year, the vastage rate was added by $15 \% . "$.

Meanwhile, according to the Head of Bebesen Health Center, Mr. dr. IV in an interview on 5 September 2021 the need for syringes, safety box b and cold chains said that:

"As far as I know, ma'am, we weren't there to plan the injection equipment, the equipment was immediately given to the health department"

According to the Bebesen Health Center immunization program manager, Mrs. M stated in an interview on 6 September 2021 that the need for injection equipment, safety box b and cold chain stated:

"It has been provided from the health office, we received the tools from the health office, we don't have any for planning the injection equipment, safety box and cold chain"

The results of an interview with the village midwife of Kampung Sadong Juru Mudi, Mrs. E, on September 7, 2021, the need for syringes, safety box b and cold chain, the need for syringes, safety box $\mathrm{b}$ and cold chain, she said that:

"In my calculations, the vaccine needs are adjusted to the target number that we will inject each month and I will add to the damage reserve of 15\%".

Meanwhile, the village midwife of Kampung Atu Gajah, Ibu R, in an interview on September 8,2021 , the need for injection equipment, safety box b and cold chain said that:

"It's been provided from the puskesmas, we just need to take the tools to the puskesmas"

Likewise, the statement from the village midwife of Kampung Mongal, Ibu A on September 4, 2021, the need for injection equipment, safety box b and cold chain said:

"As far as I know, ma'am, we didn't have any planning for the syringes, the equipment was immediately given to the health department and provided by the puskesmas, we immediately took it to the puskesmas".

Meanwhile, according to the information from the village midwife of Kampung Blang Gele, Ms. $M$ in an interview on September 9, 2021, the need for syringes, safety box b and cold chains stated that:

"We didn't make any plans, ma'am""

Meanwhile, the village midwife of Kampung Empus Talu, SM, in an interview on September 3,2021 , the need for injection equipment, safety box b and cold chain stated that:

"It has been provided from the puskesmas, we have received the tools"

The village midwife of Kampung Blang Kolak 2, SBA, in an interview on September 3, 2021, the need for injection equipment, safety box $\mathrm{b}$ and cold chain stated:

"The calculation is the same as the need for vaccines according to the target number that we will inject each month".

Based on the results of all interviews regarding the planning for the need for syringes, safety boxes and cold chains, it shows that the planning for the number of injection equipment needs, safety boxes and cold chains is carried out by the District Health Office. The need for syringes is adjusted to the number of children who will receive services based on targets and monthly targets. In line with the Regulation of the Minister of Health of the Republic of Indonesia Number 12 of 2017 concerning Guidelines for Implementing Immunization, which states that planning for the need for injection equipment and safety boxes cannot be separated from 
planning for vaccine needs. Planning for cold chain equipment was made specifically to preserve the potency of the vaccine.

\section{Implementation}

Implementation is an action or implementation of a plan that has been prepared carefully and in detail (Bryson \& Alston, 2010). Immunization program implementation is as important as planning (Sato, 2015). This includes vaccine chain management, services, waste management and recording and reporting.

\section{Vaccine Chain Management}

The following are the results of an interview with the head of the field of disease prevention and control, Dr. IW and the manager of the immunization program at the Aceh district health office, while Mr. UA took the vaccine from the Health Office to the vaccine health center:

"Continue to always maintain the quality of the chold chain so that the temperature is always in a stable condition between 2-8 C and the manager always carries out routine maintenance of the chold chain, be it daily, weekly, or monthly".

"The principle of using vaccines is that we always strive so that vaccines that are injected into the body must generate immunity and are always safe and lawful."

"The Health Office receives vaccines from the province two or three times a year, then at the health office the vaccines are stored in storage warehouses. And we will distribute it to the puskesmas once a month."

The vaccine storage system in Aceh Tengah Regency is in accordance with vaccine storage standards, which is avoiding factors that can damage the quality of vaccines. $8^{\circ} \mathrm{C}$, checking the expiry date of the vaccine, checking the vaccine monitor every day so that the vaccine does not flood and there is no frost in the refrigerator that can damage the quality of the vaccine, the vaccine should not be directly exposed to the sun.

The following are the results of an interview with the head of the Bebesen Health Center, Dr. IV and the manager of the immunization program at the Puskesmas Ibu M regarding taking vaccines from the Health Office to the Vaccine Health Center:

"We made a request for vaccines to the health office in accordance with the vaccine needs at the puskesmas.

"Daily, weekly and monthly maintenance so that the temperature remains at 2-8 C, then every holiday the cleaners also help see the temperature and report it to the person in charge of the chold chain"

"In principle, the use of vaccines must cause immunity to the body itself if it is injected and in safe conditions for the user and must always be in a halal condition."

The results of all interviews with the head of the field of disease prevention and control at the Health Office showed that the vaccination from the Health Office to the Health Center was carried out by the Immunization Program Holder directly based on the total needed by looking at the remaining vaccine stock. Vaccine collection is carried out at the beginning of every month, namely the first week or second week by bringing a vaccine carrier that has been accompanied by a cool pack.

\section{How to store vaccines}

The following are the results of an interview with the immunization program manager at the 
Puskesmas Ibu M regarding the storage and maintenance of vaccines:

"Vaccines that have been opened must be used immediately and if they are stored according to the standard, the temperature is 2-8oC. Vaccines are stored in the refrigerator, the maintenance of the vaccine is carried out by checking the temperature every day and raising the temperature chart according to the standard, besides that the room where the vaccine is stored is protected from direct sunlight and the results are reported in a book every day. If you want to see whether the vaccine can be used or not, you can't see the VVM as well. But if the vaccine is from the health office, I usually take it using a cold box and there is an attachment for proof of the goods coming out and the temperature must be maintained as well. Usually we submit a request for a vaccine to the health office, if not, I'll go straight there and take it"

Following are the results of interviews with village midwives about vaccine storage and maintenance:

"We village midwives take the vaccine ourselves and the logistics to the puskesmas are adjusted to the target number to be injected that month using the vaccine carrier that has been provided by the puskesmas".

"It is taken using a vaccine carrier and inside using a Colpack, we still maintain the temperature between 2-8 $c$ ".

"The vaccine that we inject into the baby must really be able to build immunity or the baby's immune system.".

Based on the results of all interviews regarding how to store vaccines to avoid factors that can damage the quality of vaccines, it was found that vaccine storage was appropriate, namely vaccines at the Puskesmas level were stored at a temperature of $2^{\circ} \mathrm{C}$ to $\mathrm{d} .8^{\circ} \mathrm{C}$, checking the expiry date of the vaccine, checking the vaccine monitor every day so that the vaccine does not flood and there is no frost in the refrigerator that can damage the quality of the vaccine.

Based on the results of all interviews regarding the distribution of vaccines from the Puskesmas to the place of service, it was found that the vaccine was taken in the refrigerator by considering the target who wanted to be immunized by bringing a vaccine carrier and a cool pack.

\section{Principle of use of vaccines}

The results of the interview with the Head of Disease Prevention and Control at the Health Office regarding the principles of using vaccines are obtained as follows:

"Looking at the expiration date, looking at the vaccination box, what color is it and after opening it, it is given immediately even though there is some left over from the vaccine, but it is not used because there is no one, for example, who wants to be immunized again, it cannot be stored for a long time, so it must be thrown away."

The results of the interview with the Bebesen Health Center Immunization Program Holder, Mrs. M regarding the principle of using vaccines, were obtained as follows:

"We do have a refrigerator with a record of the temperature and the expiration date is important"

The results of the interview with the Sadong Village Midwife, Juru Mudi, Mrs. E on September 7, 2021 regarding the principle of using vaccines, were obtained as follows:

"Usually if the posyandu vaccine is already open and there is a little left, it's usually not put back in the refrigerator, the vaccine is immediately thrown away because it's a

Copyright @ 2021, Journal of Asian Multicultural Research for Medical and Health Science Study, Under the license CC BY-SA 4.0 
minimum of how many hours when it's been opened."

The results of interviews regarding the principle of using vaccines in the village of Sadong Jurumudi found that vaccines that had been open for a long time were no longer used.

The results of interviews with village midwives in Kampung atu Gajah regarding the principles of using vaccines are obtained as follows:

"VVM is very important to note"

The results of interviews with village midwives from the village of Mongal regarding the principles of using vaccines are obtained as follows:

"A vaccine that has been opened cannot be used again if there is left over for a long time, so once we use it, we throw it away and if it has been left open for more than 1 hour, the quality will not be optimal"

The interview results regarding the principle of using vaccines in the Mongolian village that VVM in vaccines is very important to note and vaccines that have been left open for a long time are not reused.

The results of the interview with Belang gele regarding the principle of using vaccines were obtained as follows:

"We'll see if the vaccine changes color or not and see the prospect too"

The results of interviews with the agency in the village of blang kolak 2 regarding the principle of using vaccines are obtained as follows:

"The most important thing is to look at the expiration date before giving it and see if the white vaccine box has changed color or not"

The results of interviews regarding the principle of using vaccines in the village of blang kolak 2 showed that before administering the vaccine, first pay attention to the expiration date of the vaccine, see the change in color of the vaccine and pay attention to the condition of the VVM on the vaccine.

Based on the results of all interviews regarding the principle of using vaccines, it was found that vaccines that have been left open for a long time are not reused, pay attention to VVM on vaccines and see vaccine expiration before being given.

\section{Service}

The results of the interview with the Sadong village midwife, the helmsman regarding the preparation of officers before carrying out immunization services, explained as follows:

"Reminding cadres to announce that on that date there will be a posyandu at the Polindes"

"If the immunization service is carried out in every posyandu in our village. Prior to the implementation, the officers were prepared, the equipment was then given counseling to mothers with toddlers. Then, the cadres give announcements to mothers to bring their children to immunize when the posyandu opens, just carry out the posyandu and inject immunizations and provide a little information to the parents that the baby was injected with certain vaccines today and it will cause side effects too"

The results of the interview with Midwife Atu Gajah regarding the preparation of officers before carrying out immunization services explained as follows; 
"Remind cadres to announce that every date according to the schedule there will be a posyandu at the polindes"

"The announcement is made in the morning to bring the baby to the posyandu or polindes"

"The cadres have helped the village midwife to prepare the posyandu registration book, from table 1 to table"

"Register from table 1 and see the KMS book for what vaccines the baby needs to be injected."

The results of the interview with the Empus Talu village midwife regarding the preparation of officers before carrying out immunization services explained as follows:

"Cadres announce immunization services every day on loudspeakers, either in mosques or in their respective cadre circles"

"Conduct health education counseling before immunization services are carried out, whether it is environmental hygiene problems or family nutrition problem"

"The cadre mother helps the village midwife to prepare a good posyandu registration book from table 1 to table 5 "

"Register at table 1 and see what vaccines the baby needs to be injected"

"Implementation of the posyandu and injecting immunizations and providing a little information to the parents that the baby was injected with certain vaccines today and it will cause side effects as well"

The results of the interview with the Mongolian village midwife regarding the preparation of officers before carrying out immunization services explained as follows:

Immunization service preparation includes immunization logistics equipment as well as equipment needed for the implementation of immunization services depending on the estimated number of targets to be immunized.

The results of the interview with the Belang Kolak 2 village midwife regarding the preparation of officers before carrying out immunization services explained as follows:

"The day before the scheduled implementation of the village apparatus announced that the date on which the posyandu was held at the Polindes"

"Vaccine collection is carried out on the day of immunization carried out by the village midwife and some are delivered by the puskesmas,

"Village cadres have provided posyandu equipment and equipment, just implemented posyandu and injected immunizations and provided a little information to parents that their baby was injected with certain vaccines today and it will cause side effects too"

The results of the interview with the village midwife blang kolak 2 regarding the preparation of officers before carrying out immunization services, it was found that the preparation the day before the implementation was informed by the village apparatus and its implementation depended on the number of targets ranging from vaccines, syringes, cotton and solvents. As well as other necessary equipment such as safety boxes and cohort books.

\section{Recording and Reporting}

Recording results for immunization programs. According to the Head of the P2P Head of the 
Immunization Program, he explained that:

"Recording is done online (software, PWS Immunization and a manual reporting system that is carried out every month by puskesmas immunization officers."

According to the Regency Immunization Program Manager, Mr. UA stated that the records for the immunization program were as follows:

"Onlen system recording or using software, PWS (Local Area monitoring), and manual system reporting regarding ADS and vaccines."

Meanwhile, the results of the interview with the head of the Bebesen Health Center, dr. IV he explained that:

"Recording of immunization services is reported by the village midwife every month, then the immunization officer performs a recap of the data sent by the village midwife then an online system is recorded or using software, PWS (Local Area monitoring), which is filled in every month by the immunization and reporting officer. manual system. And it is reported to the district before the 5th at the beginning of the month"

The Bebesen Health Center Immunization Program Manager, Ibu M, stated that the recording and reporting carried out were:

"Recording is done online and manually and reports are delivered to the health office before the 5th of every month"

Reporting time for immunization results to the Puskesmas According to the Sadong village midwife, the helmsman stated that:

"Every month every 26th the report must be submitted to the puskesmas"

According to the Kampung Mongal Village Midwife who stated that:

"Reports must be submitted to the Puskesmas at the end of the month Every month"

Based on the results of all interviews regarding reporting of immunization results to the District Health Office, it shows that reporting the results of immunization activities is reported routinely every month with a maximum reporting limit of the 5 th of each month, if reporting is past the maximum date the head of the puskesmas will be reprimanded and the results of the puskesmas report will be marked. red by the Ministry of Health.

\section{Monitoring and Evaluation}

The results of the interview with the Head of $\mathrm{P} 2 \mathrm{P}$ he explained that:

"Of course it is done, but it is not in accordance with the rules that suggest we monitor every service in the field. This is due to budget constraints."

Monitoring the implementation of the immunization program according to the Regency Immunization Program Manager, Mr. UA stated that:

"Of course there are, for example, when immunization services, officers must use personal protective equipment, and explain to vaccination targets about the benefits of vaccines and remind them that their children will be given a follow-up vaccination for the following month and are reminded to come back every month to the pasyankes."

The results of interviews regarding monitoring in the implementation of the immunization program at the Bebesen Health Center with the head of the field and district immunization manager, it was found that monitoring was only by checking and seeing the report of the 
Program Holder at the time of signing the monthly report.

While monitoring the implementation of the immunization program, the Head of the Bebesen Health Center, dr. IV states that:

"Sometimes officers from the district come to monitor the implementation of vaccinations in certain villages, either immunization officers or other officers such as nutrition officers, health promotion officers"

"I also as the head of the puskesmas want to go down to the posyandu location from time to time to monitor the implementation in the field"

The Bebesen Health Center Immunization Program Manager, Ibu M, stated that:

"There is monitoring carried out by the respective program managers"

The results of interviews regarding monitoring in the implementation of the immunization program at the Bebesen Health Center showed that the Head of the Community Health Center visited the posyandu once in monitoring only by checking and viewing the report of the Program Holder when signing the monthly report.

According to all village midwife informants regarding monitoring the implementation of the immunization program, she explained that:

"There are occasional visits from the puskesmas" and Ada is evaluated by the puskesmas but there is no follow-up and guidance to us midwives in the village so that our coverage can increase"

Based on the results of all interviews with all informants in the village, it was found that monitoring had not been going well, monitoring was carried out at the stage of implementing immunization activities in the field only by immunization program holders.

\section{Evaluation}

The results of interviews with the head of the health service's disease prevention and eradication midwife regarding evaluations in the immunization program were obtained as follows:

"conducting a quarterly evaluation to find out which pockets of immunization really need attention"

Evaluation of the immunization program based on the results of interviews with the district immunization program manager, Mr. UA stated that:

"Evaluating every 3 months to the office or to the puskesmas to find out which pockets still need more frequent coaching and counseling..."

Meanwhile, according to the Head of the Bebesen Health Center, dr. IV evaluation of the immunization program he explained that:

"Evaluate the implementation of vaccination in the field and see the obstacles that occur so that the target is not achieved"

"Every 3 months when there are cross-sectoral events, we always explain the scope of programs in our area so that everyone is responsible for program achievements"

The Bebesen Health Center Immunization Program Manager, Ibu M, stated that the evaluation of the immunization program:

"yes. done every month" 
The results of interviews regarding the evaluation of the implementation of the immunization program at the Simarimbun Health Center showed that the evaluation was carried out during a mini-workshop which was held every month to discuss the results and problems faced in the field from all programs in the Puskesmas, not only the immunization program, which was attended by the Head Puskesmas and all program holders

Immunization program planning has been carried out which includes determining the number of targets, determining coverage targets, planning vaccine needs and planning for injection equipment, safety boxes and cold chain equipment needs. The implementation of the immunization program has been carried out in accordance with the Regulation of the Minister of Health of the Republic of Indonesia Number 12 of 2017 concerning Guidelines for the Implementation of Immunization including vaccine chain management, services, waste management and recording and reporting. The services provided so far have been in accordance with the standards, but community mobilization has not been carried out (Bovaird, 2007). Waste handling in the safety box is submitted by the village midwife to the Bebesen Health Center and cooperates with third parties in waste disposal. Recording and reporting of immunization results has been carried out by the village midwife to the Bebesen Health Center at the end of every month, namely every 26th. Furthermore, the immunization program manager reports to the Central Aceh District Health Office on time, which is before the 5th of each month. Monitoring and evaluation. Monitoring and evaluation of the immunization program has not been carried out in accordance with the provisions in the Regulation of the Minister of Health of the Republic of Indonesia Number 12 of 2017 concerning Guidelines for the Implementation of Immunization. The Head of the Puskesmas does not monitor immunization activities and only monitors from the report of the Program Holder (Muliawaty $\&$ Muliawaty, 2019). The evaluation has been carried out every 3 months through a tri-monthly cross-sectoral mini-workshop meeting attended by the head of the Puskesmas, crossprogrammes, village midwives, and related cross-sectors. The output of UCI coverage at the Bebesen Health Center, Central Aceh Regency has not yet reached the set target, namely the UCI achievement indicator is 98 percent of infants already IDL. The national UCI village achievement target is 100 percent, while the UCI achievement in Aceh Tengah Regency has not yet reached the set target, which is still 70.1 percent.

\section{Conclusion}

The availability of immunization program management resources, namely officers, funds, and facilities and infrastructure are up to standard. Training related to the immunization program, midwives who became informants have not received special training on immunization, the person in charge (nurse) who is an immunization officer at the Bebesen Health Center has attended technical immunization training. The implementation of the immunization program, namely planning, implementation and monitoring and evaluation has been carried out properly.

\section{Suggestion}

It is expected to carry out direct monitoring in immunization services outside the building and not only monitor the results of officers' reports and increase joint commitment across sectors and from the puskesmas to further increase cross-sectoral knowledge to improve the implementation of the immunization program so as to increase immunization coverage and achieve UCI targets.

\section{References}

Bovaird, T. (2007). Beyond engagement and participation: User and community coproduction of public services. Public administration review, 67(5), 846-860. 
Bryson, J. M., \& Alston, F. K. (2010). Creating and implementing your strategic plan: A workbook for public and nonprofit organizations (Vol. 1). John Wiley \& Sons.

Engin-Demir, C. (2009). Factors influencing the academic achievement of the Turkish urban poor. International Journal of Educational Development, 29(1), 17-29.

Engler, R. J., Nelson, M. R., Collins Jr, L. C., Spooner, C., Hemann, B. A., Gibbs, B. T., ... \& Davis, R. L. (2015). A prospective study of the incidence of myocarditis/pericarditis and new onset cardiac symptoms following smallpox and influenza vaccination. PLoS One, 10(3), e0118283.

Muliawaty, D. L., SI, M., \& Muliawaty, L. (2019, July). Implementation Of Immunization Program Policy Towards Universal Child Immunization (Uci) Achievement Village In Bandung District. In Proceedings.

Sato, A. P. S. (2015). National Immunization Program: Computerized System as a tool for new challenges. Revista de saude publica, 49.

Situmorang, T. S. (2020). Analisis Pelaksanaan Manajemen Program Imunisasi dalam Upaya Pencapaian Universal Child Immunization (UCI) di Kota Pematangsiantar. repositori.usu.ac.id 